\title{
Measuring individual feed efficiency and its correlations with performance traits in Nile tilapia, Oreochromis niloticus
}

\author{
De Verdal Hugues ${ }^{1,2}$, Mekkawy Wagdy ${ }^{2,3}$, Lind Curtis E. ${ }^{2}$, Vandeputte Marc ${ }^{4,5}$, Chatain Béatrice ${ }^{5}$,
Benzie John A.H. ${ }^{6}$
}

${ }^{1}$ CIRAD, UMR116 ISEM, TA B-116/16, 73 rue Jean-François Breton, 34398 Montpellier Cedex 5, France

${ }^{2}$ Worldfish, Jalan Batu Maung, Bayan Lepas 11960, Penang, Malaysia

${ }^{3}$ Animal Production Department, Faculty of Agriculture, Ain Shams University, Hadaeq Shubra, 11241

Cairo, Egypt

${ }^{4}$ GABI, INRA, AgroParisTech, Université Paris-Saclay, F-78350 Jouy-en-Josas, France

${ }^{5}$ Ifremer, UMR9190 MARBEC, Chemin de Maguelone, F-34250 Palavas-les-Flots, France

${ }^{6}$ School Of Biological Earth and Environmental Sciences, University College Cork, Cork, Ireland

* Corresponding author : Hugues de Verdal, email address : hugues.de verdal@cirad.fr

W.Mekkawy@cgiar.org ; C.Lind@cgiar.org ; Marc.Vandeputte@jouy.inra.fr ; Beatrice.Chatain@ifremer.fr ; J.Benzie@cgiar.org

\begin{abstract}
:
Estimating individual feed intake of fish held in groups has long been a challenge precluding precise knowledge of the individual variation of feed efficiency (FE) in fish. In this study, counts of the number of feed pellets (1.63 $\mathrm{mg}$ on average) eaten by individual tilapia (Oreochromis niloticus) held in 8 mixed sex groups of 15 fish were measured from video recordings made over a period of 10 days where fish were fed twice daily to achieve compensatory growth after 10 days of fasting. The initial body weight of the fish was $9.77 \pm 2.03 \mathrm{~g}$. Accumulated measures of feed intake (FI) over 11 meals were found to achieve $95 \%$ repeatability and a high accuracy of estimation of $\mathrm{Fl}$. During the $\mathrm{FI}$ measurement period, the average fish growth was $12.0 \pm 3.6 \mathrm{~g}$, feed intake was $0.99 \mathrm{~g}$ day- 1 , and feed conversion ratio (FCR) was $0.86 \pm 0.20$. FI differences accounted for $56 \%$ of the observed individual growth variations, and $44 \%$ was related to individual variations of $\mathrm{FE}$. On average males grew $24.2 \%$ faster than females but consumed $12.1 \%$ more feed. Males showed an $11.7 \%$ better FCR than females, whereas residual feed intake (RFI) differences were not significant between sexes. FCR and RFI were moderately and significantly correlated $(0.58 \pm 0.06)$ but $\mathrm{FCR}$ and $\mathrm{FI}$, and body weight gain (BWG) and RFI, were not, highlighting the complex relationships between feed efficiency traits. The approach described here demonstrates a means to accurately investigate FE traits in fish and to assess the potential for their genetic improvement.
\end{abstract}

\section{Statement of relevance}

Feed efficiency has strong economic and environmental impact. 


\section{Highlights}

- This is the first study to estimate FE of individual fish reared in group for an extended and continuous period of time. Provides the first accurate estimate of the phenotypic correlation between RFI and FCR in fish - Feed intake and feed efficiency traits between individual tilapias are highly variable Phenotypic differences of feed conversion ratio between males and females are significant.

Keywords : Feed efficiency, Sex, Repeatability, Nile tilapia, Feed conversion ratio, Growth, Feed intake 


\section{Introduction}

Aquaculture is playing an increasingly important role in fish supply with growth of farmed fish production greater than $1.9 \%$ per year since 1950 (Earth Policy Institute, 2013). Fish farming will play a vital role in meeting future demand (FAO, 2016). Fish have a greater feed efficiency (FE), the weight gain of animals per unit of feed consumed, compared with other livestock species (Brown, 2006). However, the cost of feed, ranging from 50 to $70 \%$ of the total production cost, is still the largest single expenditure in intensive fish farming systems (Bernier and Peter, 2001; Doupé and Limbery, 2004). Improving fish FE would thus reduce production costs but also environmental impacts caused by uneaten feed and animal waste. Consequently, it would contribute to both the economic and the environmental sustainability of farmed fish production (Besson et al, 2016). Selective breeding could be an efficient way to improve FE, but is not implemented in fish. As a prerequisite for its efficient development is the capacity to measure or at least, estimate $\mathrm{FE}$ at the individual level.

Measuring individual FE requires accurate measurement of individual feed intake (FI) during a given period of time during which body weight gain (BWG) is also measured. Most work on FE has been done on individual fish kept separately to allow measurement of feed intake (Martins et al, 2011). However, for realistic assessments of FE it is necessary to undertake assessments of fish kept in groups since social interactions between fish can have large influences on feeding behaviour (McComish, 1971; Hayward et al., 2000), and fish are normally reared collectively in production systems. The most advanced approach currently used to estimate individual FI of fish reared in a group is the use of X-radiography in which X-ray dense markers (generally radio-opaque ballotini glass beads) are included in the feed pellets (Talbot and Higgins, 1983; McCarthy et al., 1993; Silverstein et al., 2001; Jobling et al., 2001; Boujard et al., 2006; Kause et al., 2006a; Quinton et al., 2007a, b; Grima et al., 2008). Fish are X-rayed shortly after being fed this labelled feed, allowing the number of 
pellets consumed by each fish to be counted. However, the number of times these measurements can be made is limited by the need of anaesthetising and handling the fish each time they are X-rayed, and in any case this method only permits to estimate feed intake on a restricted number of meals over a period of growth where BWG is measured. As a result, individual FI over the period can only be estimated using the average of the few meals sampled. As there is low repeatability of measurements of X-ray method, (Kause et al, 2006a; Grima et al., 2008) this raises questions about its accuracy and relevance.

This led some researchers to investigate potential indirect individual predictors of FE, such as weight loss at fasting and compensatory growth, which were shown to be correlated to FE in rainbow trout Oncorhynchus mykiss (Grima et al, 2008) and European sea bass Dicentrarchus labrax (Grima et al, 2010).

Alternatively, FI can be measured for each fish by counting the number of pellets eaten during a given time span. External individual identification of each fish is needed and care has to be taken concerning the presence of observers as this can influence feeding behaviour. Video recording the number of feed pellets eaten by each fish has been mentioned as an approach that could address the issue of the presence of observers some time ago (Jobling et al. 2001). However, this technique appears to have been rarely used for FI measurement in an aquaculture context (Kadri et al., 1996) but has been used for analysing fish behaviour, for example, on choice of feeds or effect of aggressive interactions on feed intake (Hart and Salvanes, 2000; Goldan et al., 2003).

We used this approach to estimate individual FI and to calculate estimates of FE and phenotypic correlations with performance traits in Nile tilapia Oreochromis niloticus, comparing data for males and females, which shown strong differences in growth. The development of accurate methods to estimate individual $\mathrm{FE}$ and knowledge of the relation between growth and FE variables are necessary for assessing the feasibility of genetic 
selection as a means of improving of FE. The specific objectives of the present study were 1) to determine the minimum number of meals to be measured to have an accurate estimate of FI and FE of individual fish over an extended period 2) to measure FI and FE and their relationships, estimating the differences between males and females and 3) to estimate the relationships between FE and other performance traits, especially weight loss at fasting and compensatory growth which were previously shown to be indicator traits of individual FE.

\section{Material and Methods}

\subsection{Rearing of fish}

The study was carried out on the GIFT strain of Nile tilapia produced by natural spawning in December 2014 by WorldFish at the Jitra Research station, Malaysia. After hatching, larvae were kept in hapas in ponds until their transfer to the Penang WorldFish station where they were reared until the fry reached approximately $10 \mathrm{~g}$ of body weight. After a one-week quarantine in tanks, 120 fish weighing $9.77 \pm 2.03$ were dispatched to 8 aquaria in a recirculating water system, with 15 fish per $100 \mathrm{~L}$ indoor tanks $(120 \mathrm{~cm}$ length, $35 \mathrm{~cm}$ width and $24 \mathrm{~cm}$ depth). The recirculating system included a biological and sand filters, with a renewal water rate at $100 \%$ per hour and constant aeration. The average temperature was 28 $\pm 1^{\circ} \mathrm{C}$ and the photoperiod 12L:12D. Two coloured T-bar tags (Avery Dennison tags, 25mm) were inserted in each fish (using an Avery Dennison Mark III pistol Grip tool) in the dorsal muscle, close to the dorsal fin, after the fish had been anaesthetized with clove oil. A different colour combination was used for every fish within an aquarium so that each fish could be individually identified. The needles used to insert the tags were cleaned with alcohol between each fish. Fish were fed a commercially available tilapia feed (34\% crude proteins, $5 \%$ crude fat, $5 \%$ crude fiber and $12 \%$ moisture) at a daily rate calculated according to Mélard et al. (1997) as follows: 


$$
\mathrm{DFR}=14.23 * \mathrm{BW}^{-0.322}
$$

where DFR is the daily food ration, expressed in \% of body weight (BW) per day and BW is the average body weight of the fish within each aquarium. Mortality was recorded daily and feed ration changed accordingly. Fish were not fed until apparent satiation because this method is widely variable from a person to another which reduce repeatability of the experiment and increase the aquarium effect.

2.2. Feed intake measurements and analyses

After an adaptation period of two weeks in aquaria, fish were anaesthetized with clove oil and weighed. A period of 10 days of fasting was followed by a period of 17 days where fish were fed twice daily to achieve compensatory growth. Ten days of fasting was decided after preexperiment testing the mortality rate after several days of fasting, and was in accordance with Wang et al. (2009). At the end of both fasting and compensatory growth periods, fish were anaesthetized with clove oil and their BW measured. The loss of weight during the fasting period was calculated as the difference in BW between the beginning and the end of this period and from hereon is referred to as 'LOSS'. In the same way, the gain in BW during the compensatory growth period was calculated as the difference of BW between the beginning and the end of this period, which was also the beginning of the individual evaluation period (BWi) and from hereon is referred to as 'COMP'. After the compensatory growth period, FI was recorded for each fish over a period of 10 days to estimate FE traits. During this individual FI measurement period, feed was delivered to each aquarium pellet by pellet by hand through two pipes in view to reduce the proximity between the experimenter and the aquarium, twice daily at 7.00 am and $1.00 \mathrm{pm}$ (except for the first day where fish were weighed the morning, and fed only once in the afternoon) until the calculated feed ration was 
distributed. Each meal was video recorded and individual FI was then calculated by video analyses counting the number of pellets eaten by each fish for each meal. After 10 days of FI measurement (19 meals), fish were anaesthetised with clove oil and weighed (BWf). The body weight gain (BWG) during the individual FI measurement period, was calculated as the difference between BWf and BWi. The day after the end of the FI measurement period, fish were anaesthetised and killed by decapitation, and sexed by visual observations of the gonads.

The video analyses were performed using Kinovea 0.8.15 software (Copyright @ 2006-2011 Joan Charmant \& Contrib.), which provided the capability to increase or reduce the speed and to zoom in or out for more detailed observation of an event. For each aquarium, 19 meals were recorded, each fish then having 19 FI values, one per meal. As pellet weight variability, in terms of standard deviation (SD) and coefficient of variation (CV), was reasonably low (Mean=16.4 $\pm \mathrm{SD}=1.76 \mathrm{mg}, \mathrm{CV}=10.7 \%$ ) it was assumed that each pellet had the same weight, allowing the calculation of FI in grams for each meal. The total FI for an individual was calculated as the sum of the FI of all meals consumed.

The feed conversion ratio (FCR=FI/ BWG) was used as an indicator of feed efficiency, which is more commonly used than its inverse, the feed efficiency ratio FER=BWG/FI. The residual feed intake (RFI) is defined as the difference between feed consumed by an animal and its predicted consumption estimated by a regression model taking into account the feed requirements for maintenance and growth as independent variables (Koch et al., 1963; Doupé and Limbery, 2003; Martins et al., 2011). The equation used to estimate RFI was as follow:

$$
\mathrm{RFI}=\mathrm{FI}-\beta_{0}-\beta_{1} * \mathrm{BW}^{0.8}-\beta_{2} * \mathrm{BWG}
$$

with FI the feed intake, $\beta_{0}$ the regression intercept, $\beta_{1}$ the partial regression coefficient of animal's FI on metabolic body weight, $\mathrm{BW}^{0.8}$ the metabolic body weight using the metabolic body coefficient developed by Lupatsch et al. (2003), $\beta_{2}$ the partial regression coefficient of 
animal's FI on BWG, and RFI which corresponds to the residual of the model. Individuals with positive RFI consume more than the average of fish with the same body weight and body weight gain whereas animals with negative RFI consume less, suggesting the latter are more efficient at converting feed to gain. The parameters of the regression equation were estimated using the REG procedure of SAS (version 9.3, SAS Institute, Cary NC).

\subsection{Statistical analyses}

The normality of the data was tested using the Shapiro-Wilk test on R 2.15.3 software. All the data were normally distributed except FCR and this trait was log transformed to match the normal distribution.

The means, standard deviations and coefficients of variation (CV) were calculated using $\mathrm{R}$ software (R Core Team, 2013).

To estimate the repeatability of the measurements, intra-class correlation coefficients (ICC), indicating the part of the total phenotypic variance explained by permanent differences between individuals were estimated. Package "ICC" (Wolak et al., 2012) under R software was used for this analysis. This package allows an estimation of the ICC and the confidence interval limit.

Using a Bayesian approach, the bivariate correlations between all studied traits were estimated as well as all bivariate correlations between the FI of each individual fish for each of the 19 meals. For the bivariate correlations, we assumed an inverse Wishart conjugate prior distribution of the variance-covariance matrix. Package "rjags" (Plummer, 2011) under R software was used for the analysis. The correlations between the total FI of all meals together and FI for a specific number of meals ranging from 1 to 18 meals (randomly or consecutively 
chosen) were also estimated. For all analyses, Gibbs sampling was used to estimate the marginal posterior distributions of all parameters. A chain of 20,000 iterations was used, with a burn-in of 2,000 iterations and lag of 10. A further 1,800 iterations were used for the calculation of posterior means and posterior standard deviation of the correlations.

To assess the effect of sex on the studied traits, a model including the sex effect was used in a Bayesian analysis. A bounded, flat prior was assumed for the sex effect, and a conjugate inverse gamma distribution was assumed for the residual variance. The analyses were performed using software written for the project. A chain of 60,000 iterations was used with a burn-in of 10,000 iterations and lag of 10. A 50,000 iterations chain was used for the calculation of the posterior means, posterior standard deviations and highest posterior density at $95 \%\left(\mathrm{HPD}_{95 \%}\right)$.

To test if the general model used to estimate RFI was applicable to both sexes, an heterogeneity of slopes model was tested with the GLM (General Linear Model) procedure of SAS (version 9.3, SAS Institute, Cary NC):

$$
\mathrm{FI}_{\mathrm{ij}}=\mu+\mathrm{S}_{\mathrm{i}}+\beta_{1} * \mathrm{BW}^{0.8}+\beta_{2} * \mathrm{BWG}+\beta_{3} *\left(\mathrm{~S}_{\mathrm{i}}\right) \mathrm{BW}^{0.8}+\beta_{4} *\left(\mathrm{~S}_{\mathrm{i}}\right) \mathrm{BWG}+\mathrm{e}_{\mathrm{ij}}
$$

Where $\mathrm{FI}_{\mathrm{ij}}$ is the FI of the fish $\mathrm{j}, \mu$ is the general mean, $S_{\mathrm{i}}$ is the fixed effect of the sex $\mathrm{i}$ and $\mathrm{e}_{\mathrm{ij}}$ is the residual pertaining to fish $\mathrm{j}$.

\section{Results}

\subsection{Accuracy of the FI measurements}

Given the average number of pellets eaten by an individual fish per meal was 31.8 , the average FI per fish and per meal was $31.8 * 16.4=522 \mathrm{mg}$, and its standard error was $1.76^{*}(31.8)^{0.5}=9.92 \mathrm{mg}$, or approximately $1.9 \%$ of the estimated FI per meal. Furthermore, 
the coefficient of variation of FI within a meal is estimated at $35.7 \%$ (Table 1). The posterior means of the correlations between each meal taken separately were highly variable, ranging from 0.09 to 0.70 , with a mean of all the correlations of $0.45 \pm 0.11$ (Table SupplA).

To reach a correlation greater than 0.95 between the total FI in all 19 meals and an indicator using the mean FI in only some of the meals, it was necessary to take into account 9 consecutive meals or 7 randomly chosen meals (Figure 1). The posterior standard deviation of the correlation decreased with an increasing number of meals taken into account, from 0.06 for 1 meal to 0.01 for 9 meals, which shows an increase in the accuracy of the estimate when more meals are measured.

The repeatability of this specific FI measurement was estimated with the ICC, which was 0.42. ICC was also calculated taking into account the meal of 2 to 19 meals, chosen randomly or consecutively. Whether random or consecutive meals were taken into account, results were similar. The repeatability is higher than 0.95 when 11 meals or more were averaged (Figure 2).

\subsection{Impact of sex on feed efficiency traits}

The differences between male and female were considered significant if the $\mathrm{HPD}_{95 \%}$ interval of differences did not include 0, which is the case for LOSS, COMP, BWG, FCR, log FCR and FI, but not for RFI (Table 2, Figure 3). Consequently, there is an important difference observed between sexes for all variables except RFI. The impact of fasting is lower and gain during compensatory growth is greater in males compared to females. On average, compared to females, males gained $24.2 \%$ more weight during the FI measurement period but consumed only $12.1 \%$ more feed. Males showed an $11.7 \%$ better (lower) FCR compared to females, whereas RFI differences were not significant between sexes. 
The relation between observed and predicted FI (Figure 4) is similar between males and females, with comparable slopes of the regression lines. This similarity is proven by the lack of significance of all sex-linked effects in the heterogeneity of slopes test (model 3), with $\mathrm{P}>0.60$ for the fixed effect of sex, $\mathrm{P}>0.91$ for the sex-specific regression coefficient on metabolic body weight and $\mathrm{P}>0.44$ for the sex-specific regression coefficient on BWG.

\subsection{Feed efficiency characteristics}

During the fasting-refeeding challenge, fish lost on average $0.14 \pm 0.03 \mathrm{~g}$ of BW per day during the feed deprivation period and gained $0.94 \pm 0.23 \mathrm{~g}$ of BW per day during the compensatory growth period (Table 3).

During the full FI measurement period (10 days, 19 meals), fish growth was on average 12.0

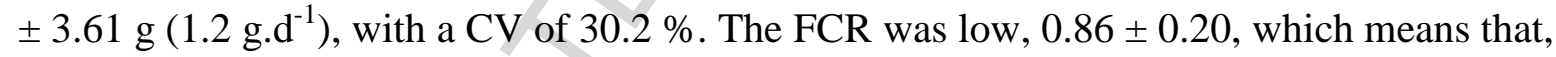
for each gram of feed consumed, the fish grew of $1.2 \mathrm{~g}$ but that there was wide variation between fish in terms of individual FCR, as shown by the $23.4 \%$ coefficient of variation, the extremes being 0.56 and 1.78 . The mean of RFI was zero as expected since the average is considered as the base point to compare feed efficiency between fish. The metabolic body weight $\mathrm{BW}^{0.8}$ and $\mathrm{BWG}$ were both significant $(\mathrm{P}<0.0001)$ in the regression equation for FI. The general prediction equation of RFI was as follows:

$$
\mathrm{RFI}=\mathrm{FI}-0.734-0.346 * \mathrm{BW}^{0.8}-0.325 * \mathrm{BWG}
$$

As expected, the correlation between BWG and FI was positive $(0.74 \pm 0.05$, Table3) showing that there is significant variation in FCR. There was a significant negative correlation between BWG and FCR $(-0.62 \pm 0.06)$, but not between BWG and RFI $(-0.03 \pm 0.10)$. Neither the loss of weight during feed deprivation nor the gain of weight during the refeeding 
period was correlated to any of the FE traits (Table 4). Gain of weight during the refeeding period was correlated with BWG and FI. The correlations were not significant between FCR (or logFCR) and FI, nor between BWG and RFI. The correlation between FCR and RFI was positive but moderate $(0.58 \pm 0.06)$.

\section{Discussion}

\subsection{Accuracy of the FI measurements}

The first objective of the present study was to determine how many meals had to be measured in order to accurately estimate FI over a given period of time, in order to accurately estimate FE traits for individual fish held in groups. The most widely used method to date using X-ray methods has a low repeatability (range 0.09-0.32) between two individual measurements in a given experiment (Kause et al., 2006a; Grima et al., 2008). In the present study, the repeatability of individual FI measurements was 0.42 , better but still not accurate enough. The repeatability and the overall accuracy of the estimation of FI were improved by taking several meals into account. The repeatability between two meals and two other meals is $47.6 \%$ higher than between two single meals. In the present study, it was necessary to include measurements of $58 \%$ (11 out of 19 meals) of all meals given over the 10 day period to achieve a repeatability of $95 \%$. This is regardless of whether consecutive or random meals were considered. Further investigation is needed to understand how this may also vary for different ages and species of fish, but is likely that preliminary experimentation will be required to determine the optimum number of meals needed to be measured to ensure a given level of accuracy in FI estimation for each particular circumstance.

\subsection{Impact of sex on feed efficiency traits}


Aquaculture of Nile tilapia is generally focused on all male production, for two main reasons.

The first one is the fact that a low proportion of females limits the unwanted increase of population density into the ponds due to natural reproduction, which can occur quickly in tilapia. The second reason is the existence of a sex dimorphism for body size in favour of males (Lazard, 1980; Toguyeni et al., 1997, Lind et al., 2015), which is beneficial to producers. The present results are in agreement with the general observation that males grow faster than females and are in accordance with results of Toguyeni et al. (1997) who estimated that the FCR of males was significantly better than that of females. It is interesting to highlight that whereas males ate more than females, their FCR was significantly lower, due to higher growth than females, confirming that from the perspective of FCR, it is more beneficial to rear males than females with both an economic and an environmental benefit.

The links between sexual size dimorphism, FI and FE have not been studied until now, due to the absence of reliable ways to estimate FI. Since FCR was only correlated to BWG and not to FI, the differences of FCR between males and females are likely linked to the single growth differences. This hypothesis is supported by the lack of significant differences between sexes for RFI, which are not linked to the general prediction equation. This finding highlights the fact that FCR and RFI are not the same trait and consequently, care needs to be taken in which trait is targeted in attempting to genetically improve FE characteristics. According to several studies, the differences in RFI can be essentially due to differences in maintenance requirements (Luiting and Urff, 1991; Herd and Bishop, 2000; Martins et al., 2005). This suggests that there is no difference of maintenance requirements between male and female Nile tilapia in the present study, which is also reinforced by the non-significant difference of the sex-specific partial regression coefficient for $B W^{0.8}$ in Model 3. In the same way, since there are no significant differences for the sex-specific partial regression coefficient for BWG, it can be hypothesized that the feed requirements for growth are not different in males and 
females - and that the better FCR of males is just due to their faster growth, which mechanically reduces the share of maintenance requirements in the use of the ingested feed. It is also important to highlight that the variability of these feed efficiency traits is close between males and females, which could be of interest for a genetic selection program on feed efficiency traits since males and females would answer to the selection process. In future studies, it would be of interest to measure these traits on older, mature fish to understand the kinetics of FE traits in relation to age, sex and sexual maturity, and see if differential maturation may, at some point, generate differences in FE between males and females.

\subsection{Feed efficiency characteristics}

The average daily gain was 1.2 g.day ${ }^{-1}$, which is slightly greater than previously reported, ranged from 0.7 to 1.06 (Siddiqui et al., 1991). This may be explained by the strain used in the present study, the GIFT strain, which has been genetically selected for growth for more than 20 generations (Eknath et al., 2007; Ponzoni et al., 2011). Regarding FE traits, FCR (0.86 \pm 0.20) was in the lower range of previously published estimates on groups of tilapia, generally ranging from 1.1 to 1.85 (El-Sayed and Kawanna, 2004; Koumi et al., 2011). It is not possible to conclude that the differences between the estimates are explained by the protocol used to measure FI (in group rather than in individual fish) as there were many differences between these experiments (e.g. strain used, the age of fish used, the specific conditions of the experiments).

Given that FE is the ratio between BWG and FI, it is important to consider the relationship between these two traits. The determination coefficient $r^{2}$ of the linear regression between FI and BWG is 0.56 . This implies that FI differences accounted for $56 \%$ of the observed variance of individual growth, which means that the remaining $44 \%$ were related to the 
individual variation of FE. This relation between FI and BWG is lower than that previously reported by Martins et al. (2011), who estimated $\mathrm{r}^{2}=0.81$, but with individual FI measurements on isolated fish, which omits the effects of social interactions. Such individual rearing has been shown to improve FI and FE of the fish compared to group rearing (McComish, 1971; Hayward et al., 2000). However, the correlation between FI and BWG in our experiment is comparable to previous estimates in fish, which range from 0.51 to 0.98 (Kolstad et al., 2004; Doupé and Limbery, 2004; Kause et al., 2006b; Quinton et al., 2007a; Martins et al., 2011) with the caveat that the previous measurements were made with less accurate methods using X-ray or direct measurement of feed intake of the family group rather than on the individual.

In the present study, the phenotypic correlations between LOSS, COMP and FE traits were low and not different from 0. Grima et al. (2010) observed that European seabass phenotypically selected for low weight loss during fasting showed an improved RFI, with little even no effect of compensatory growth. The same authors, in rainbow trout, showed that RFI was improved by the combination of low weight loss at fasting and high compensatory growth (Grima et al., 2008). It appears that in tilapia, the relationship between those traits seems to differ, and that neither the weight loss at fasting nor the compensatory growth are predictive of RFI or FCR, at least in our conditions.

In addition to setting up an accurate methodology to estimate an individual FE, understanding the relationships between FE and other performance traits is of importance to estimate the potential impact of a genetic selection for FE in fish. In our study, FCR and RFI did not have the same pattern of phenotypic correlations with FI and BWG: whereas FCR was correlated with growth, RFI was not. The latter result was expected since RFI is recognized as phenotypically independent of growth. In contrast, whereas RFI was correlated with FI, FCR was not. The lack of any correlation between FCR and FI was not expected, as FCR is the 
ratio between FI and BWG, and FCR expected to be linked with both variables. These results can have a high impact if a selection scheme is developed using FCR or RFI as criteria, since such selections may impact different metabolic processes, and the selection response would be different. This is supported in the present study by the moderate correlation between FCR and RFI.

Estimations of RFI and FCR are scarce in fish. To our knowledge, the present study is the first to accurately estimate the phenotypic correlation between these two FE traits in fish. This correlation $(0.58 \pm 0.06)$ is at the lower limit of the correlations generally found in livestock species, ranging between 0.6 and 0.8 (Herd and Bishop, 2000; Arthur et al., 2001; Rauw et al., 2006; Saintillan et al., 2013). Energy intake from the feed is used as growth, maintenance requirement and physical activities. Since fish are poikilotherms, the energy used for maintenance is lower than for livestock species, which could potentially explain the lower correlation between RFI and FCR in fish.

\section{Conclusion}

The present paper is the first to measure individual feed efficiency in fish held in groups over a continuous period of time rather than interspersed time points separated by several days or weeks. We showed that estimating FI, FCR and RFI with a high repeatability and accuracy can be achieved in the case of tilapia by integrating measurements over 11 meals. These traits showed a high phenotypic variability, which is encouraging for future studies aimed at understanding the underlying genetic variation for FE traits in fish and their potential incorporation into fish selection schemes. We highlight the importance of treating FE traits differently. Given RFI is phenotypically independent of the growth of the fish, selection for growth may have an indirect response on FCR but not on RFI, and the effects of direct 
selection on FE traits (FCR or RFI) will be different according to the FE trait selected. However, it is important to note that all the correlations estimated in the present paper are phenotypic correlations; it would be important to consider the genetic correlations of these traits to conclude the impact of a selection process on feed efficiency. It also would be interesting to analyse the relations between feed efficiency traits and behaviours. Hierarchy could have a high impact on these traits, while from preliminary results using the same methodology, hierarchy was not significantly correlated with feed efficiency (unpublished data). Finally, compare the feed efficiency traits of groups of males alone, females alone and mixed sexes could be interesting to understand the impact of the sex on these traits, with a relation to the behaviours modifications due to the sex of the group.

\section{Conflict of interest}

The authors declare that they have no conflict of interest.

\section{Acknowledgements}

We thank Hooi Ling Khaw, Hoong Yip Yee and Khairul Rizal Abu Bakar for the supply of fish and maintenance of the water system, Marie-Laure Bégout for advice on visual tagging, and colleagues who improved this work through commenting on earlier drafts. This study contributes to the CGIAR Research Program on Livestock and Fish. 


\section{References}

Arthur, P.F., Archer, J.A., Johnston, D.J., Herd, R.M., Richardson, E.C., Parnell, P.F., 2001. Genetic and phenotypic variance and covariance components for feed intake, feed efficiency, and other postweaning traits in Angus cattle. Journal of Animal Science. $79,2805-2811$.

Bernier, N.J., Peter, R.E., 2001. The hypothalamic-pituitary-interrenal axis and the control of food intake in teleost fish. Comparative Biochemistry and Physiology: Part B. 129, 639-644.

Besson, M., Aubin, J., Komen, H., Poelman, M., Quillet, E., Vandeputte, M., Van Arendonk, J.A.M., de Boer, I.J.M., 2016. Environmental impacts of genetic improvement of growth rate and feed conversion ratio in fish farming under rearing density and nitrogen output limitations. Journal of Cleaner Production. 116, 100-109.

Boujard, T., Cuvier, A., Geurden, I., Labbé, L., Mambrini, M., 2006. Selection for growth and feeding hierarchy in brown trout. Applied Animal Behavior Science. 99, 344-356.

Brown, L.R., 2006. Plan B 2.0: Rescuing a planet under stress and a civilization in trouble. http://www.earth-policy.org/books/pb2.

Doupé, R.G., Lymbery, A.J., 2003. Toward the genetic improvement of feed conversion efficiency in fish. Journal of the World Aquaculture Society. 34, 245-254.

Doupé, R.G., Lymbery, A.J., 2004. Indicators of genetic variation for feed conversion efficiency in black bream. Aquaculture Research. 35, 1305-1309.

Earth Policy Institute, 2013. World animal production by type, 1950-2012. in: Earth Policy Institute, (Ed.). http://www.earth-policy.org/data_center/C24, published online 12 June 2013.

Eknath, A.E., Bentsen, H.B., Ponzoni, R.W., Rye, M., Nguyen, N.H., Thodesen, J., Gjerde, B., 2007. Genetic improvement of farmed tilapias: Composition and genetic 
parameters of a synthetic base population of Oreochromis niloticus for selective breeding. Aquaculture. 273, 1-14.

El-Sayed, A.-F., Kawanna, M., 2004. Effects of photoperiod on the performance of farmed Nile tilapia Oreochromis niloticus: I. Growth, feed utilization efficiency and survival of fry and fingerlings. Aquaculture. 231, 393-402.

FAO, 2016. http://www.fao.org/fishery/statistics/global-aquaculture-production/fr

Goldan, O., Popper, D., Karplus, I., 2003. Food competition in small groups of juvenile gilthead sea bream (Sparus aurata). The Israeli Journal of Aquaculture - Bamidgeh. $55,94-106$.

Grima, L., Quillet, E., Boujard, T., Robert-Granié, C., Chatain, B., Mambrini, M., 2008. Genetic variability in residual feed intake in rainbow trout clones and testing of indirect selection criteria. Genetic Selection Evolution. 40, 607-624.

Grima, L., Vandeputte, M., Ruelle, F., Vergnet, A., Mambrini, M., Chatain, B., 2010. In search for indirect criteria to improve residual feed intake in sea bass (Dicentrarchus labrax). Part I: Phenotypic relationship between residual feed intake and body weight variations during feed deprivation and re-feeding periods. Aquaculture. 300, 50-58.

Hart, P.J.B., Salvanes, A.G.V., 2000. Individual variation in competitive performance of juvenile cod and its consequences for growth. Journal of the Marine Biological Association of the UK. 80, 569-570.

Hayward, R.S., Wang, N., Noltie, D.B., 2000. Group holding impedes compensatory growth of hybrid sunfish. Aquaculture. 183, 299-305.

Herd, R.M., Bishop, S.C., 2000. Genetic variation in residual feed intake and its association with other production traits in British Hereford cattle. Livestock Production Science. 63, 111-119. 
Jobling, M., Covès, D., Damsgård, B., Kristiansen, H.R., Koskela, J., Petursdottir, T.E., Kadri, S., Gudmundsson, O., 2001. Techniques for measuring feed intake. in: Houlihan, D., Boujard, T., Jobling, M. (Eds.), Food intake in fish. Wiley-Blackwell, pp. $49-87$.

Kadri, S., Huntingford, F.A., Metcalfe, N.B., Thorpe, J.E., 1996. Social interactions and the distribution of food among one-sea-winter Atlantic salmon (Salmo salar) in a seacage. Aquaculture. 139, 1-10.

Kause, A., Tobin, D., Dobly, A., Houlihan, D., Martin, S., Mäntysaari, E.A., Ritola, O., Ruohonen, K., 2006a. Recording strategies and selection potential of feed intake measured using the X-ray method in rainbow trout. Genetic Selection Evolution. 38, 389-409.

Kause, A., Tobin, D., Houlihan, D.F., Martin, S.A.M., Mäntysaari, E.A., Ritola, O., Ruohonen, K., 2006b. Feed efficiency of rainbow trout can be improved through selection: Different genetic potential on alternative diets. Journal of Animal Science. 84, 807-817.

Koch, R.M., Swiger, L.A., Chambers, D., Gregory, K.E., 1963. Efficiency of feed use in beef cattle. Journal of Animal Science. 22, 486-494.

Kolstad, K., Grisdale-Helland, B., Gjerde, B., 2004. Family differences in feed efficiency in Atlantic salmon (Salmo salar). Aquaculture. 241, 169-177.

Koumi, A.R., Koffi, K.M., Atsé, B.C., Kouame, L.P., 2011. Growth, feed efficiency and carcass mineral composition of Heterobranchus longifilis, Oreochromis niloticus and Sarotherodon melanotheron juveniles fed different dietary levels of soybean mealbased diets. African Journal of Biotechnology. 10, 14990-14998. 
Lazard, J., 1980. Le développement de la pisciculture intensive en Côte d'Ivoire: Exemple ferme piscicole pilote de Natio-Kobadara (Korhogo). Revue Bois et Forêts des Tropiques. 190, 45-66.

Lind, C.E., Safari, A., Agyakwah, S.K., Attipoe, F.Y.K., El-Naggar, G.O., Hamzah, A., Hulata, G., Ibrahim, N.A., Khaw, H.L., Nguyen, N.H., Maluwa, A.O., Zaid, M., Zak, T., Ponzoni, R.W., 2015. Differences in sexual size dimorphism among farmed tilapia species and strains undergoing genetic improvement for body weight. Aquaculture Reports. 1, 20-27.

Luiting, P., Urff, E.M., 1991. Optimization of a model to estimate residual feed consumption in the laying hen. Livestock Production Science. 27, 321-338.

Lupatsch, I., Kissil, G.W., Sklan, D., 2003. Comparison of energy and protein efficiency among three fish species gilthead sea bream (Sparus aurata), European sea bass (Dicentrarchus labrax) and white grouper (Epinephelus aeneus): energy expenditure for protein and lipid deposition. Aquaculture. 225, 175-189.

Martins, C.I.M., Schrama, J.W., Verreth, J.A.V., 2005. The consistency of individual differences in growth, feed efficiency and feeding behaviour in African catfish Clarias gariepinus (Burchell 1822) housed individually. Aquaculture Research. 36, 15091516.

Martins, C.I.M., Conceiçao, L.E.C., Schrama, J.W., 2011. Feeding behavior and stress response explain individual differences in feed efficiency in juveniles of Nile tilapia Oreochromis niloticus. Aquaculture. 312, 192-197.

McCarthy, I.D., Houlihan, D.F., Carter, C.G., Moutou, K., 1993. Variation in individual food consumption rates of fish and its implications for the study of fish nutrition and physiology. Proceedings of the Nutrition Society. 52, 427-436.. 
McComish, T.S., 1971. Laboratory experiments on growth and food conversion by the bluegill. University of Missouri, Columbia, pp. 203.

Mélard, C., Baras, E., Desprez, D., 1997. Compensatory growth of Nile tilapia Oreochromis niloticus. in: Fitzsimmons, K. (Ed.), Fourth International Symposium on Tilapia in Aquaculture. Northeast Regional Agricultural Engineering Service, Orlando, Florida, USA.

Plummer, M., 2011. rjags: Bayesian graphical models using MCMC. URL http://CRAN.Rproject.org/package=rjags.

Ponzoni, R.W., Hong Nguyen, N., Khaw, H.L., Hamzah, A., Abu Bakar, K.R., Yee, H.Y., 2011. Genetic improvement of Nile tilapia (Oreochromis niloticus) with special reference to the work conducted by the WorldFish Center with the GIFT strain. Reviews in Aquaculture. 3, 27-41.

Quinton, C.D., Kause, A., Koskela, J., Ritola, O., 2007a. Breeding salmonids for feed efficiency in current fishmeal and future plant-based diet environment. Genetic Selection Evolution. 39, 431-446.

Quinton, C.D., Kause, A., Ruohonen, K., Koskela, J., 2007b. Genetic relationships of body composition and feed utilization traits in European whitefish (Coregonus larvaretus L.) and implications for selective breeding in fishmeal- and soybean meal-based diet environments. Journal of Animal Science. 85, 3198-3208.

R Core Team, 2013. R: A language and environment for statistical computing. R Foundation for Statistical Computing, Vienna, Austria. URL http://www.R-project.org/.

Rauw, W.M., Soler, J., Tibau, J., Reixach, J., Raya, L.G., 2006. The relationship between residual feed intake and feed intake behavior in group-housed Duroc barrows. Journal of Animal Science. 84, 956-962. 
Saintilan, R., Mérour, I., Brossard, L., Tribout, T., Dourmad, J.Y., Sellier, P., Bidanel, J.P., van Milgen, J., Gilbert, H., 2013. Genetics of residual feed intake in growing pigs: Relationships with production traits, and nitrogen and phosphorus excretion traits. Journal of Animal Science. 91, 2542-2554.

Siddiqui, A.Q., Howlader, M.S., Adam, A.E., 1991. Effects of water exchanges on Oreochromis niloticus (L.) growth and water quality in outdoor concrete tanks. Aquaculture. 95, 67-74.

Silverstein, J.T., Bosworth, B.G., Waldbieser, C.G., Wolters, W.R., 2001. Feed intake in channel catfish: is there a genetic component? Aquaculture Research. 32 (Suppl 1), 199-205.

Talbot, C., Higgins, P.J., 1983. A radiographic method for feeding studies on fish using metallic iron powder as a marker. Journal of Fish Biology. 23, 211-220.

Toguyeni, A., Fauconneau, B., Boujard, T., Fostier, A., Kuhn, E.R., Mol, K.A., Baroiller, J.F., 1997. Feeding behaviour and food utilisation in tilapia, Oreochromis niloticus: effect of sex ratio and relationship with the endocrine status. Physiology \& Behavior. $62,273-279$.

Wang, Y., Li, C., Qin, J.G., Han, H., 2009. Cyclical feed deprivation and refeeding fails to enhance compensatory growth in Nile tilapia, Oreochromis niloticus L. Aquaculture Research. 40, 204-210.

Wolak, M.E., Fairbairn, D.J., Paulsen, Y.R., 2012. Guidelines for estimating repeatability. Methods in Ecology and Evolution. 3, 129-137. 


\section{Figures}

Figure 1 - Estimation of the posterior means of the correlations between FI (19 meals) and $\mathrm{x}$ consecutive (in black) and randomly chose (in grey) meals (from 1 to 19).

Figure 2 - Estimation of the intra-class correlation (ICC) between FI (19 meals) and x consecutive (in black) and randomly chose (in grey) meals (from 1 to 19).

Figure 3 - Posterior distributions of the least squares means (density) of males and females for different studied traits. BWG, body weight gain (g); FItotal, feed intake total (g); FCR, feed conversion ration; and RFI, residual feed intake.

Figure 4 - Regression between observed and predicted FI with model 3 for males (in black) and females (in grey) 


\section{Figure 1}

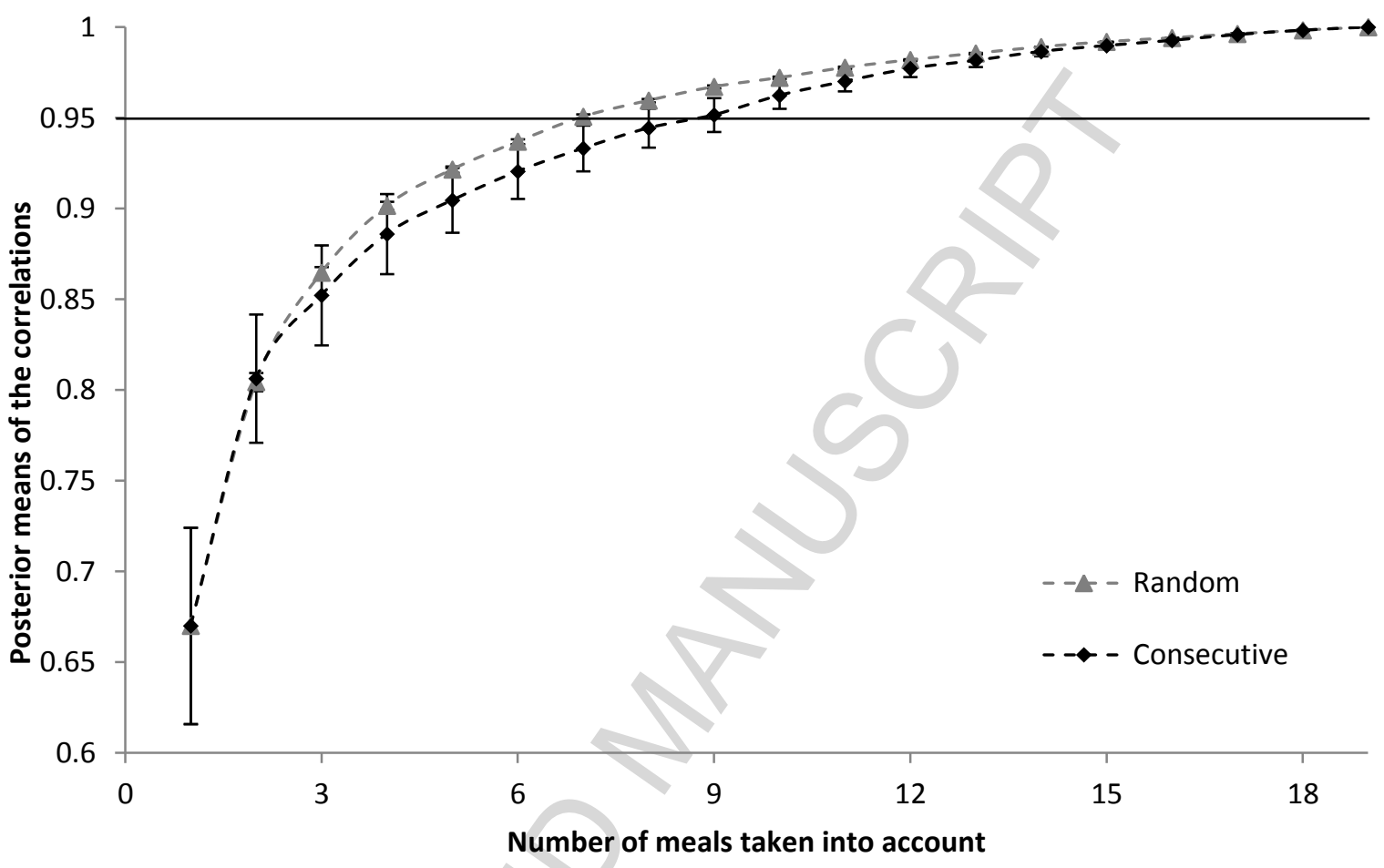


Figure 2

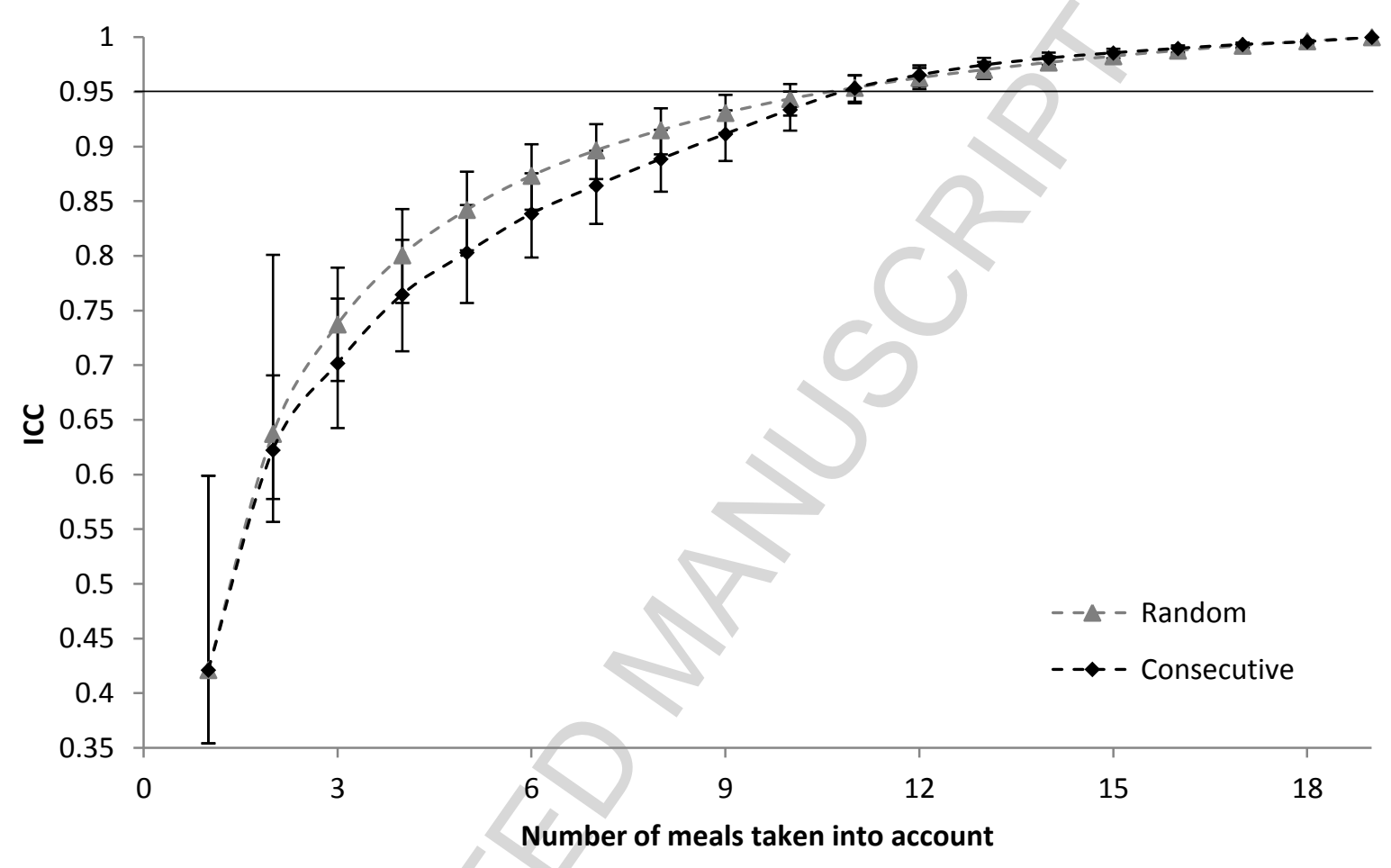


Figure 3
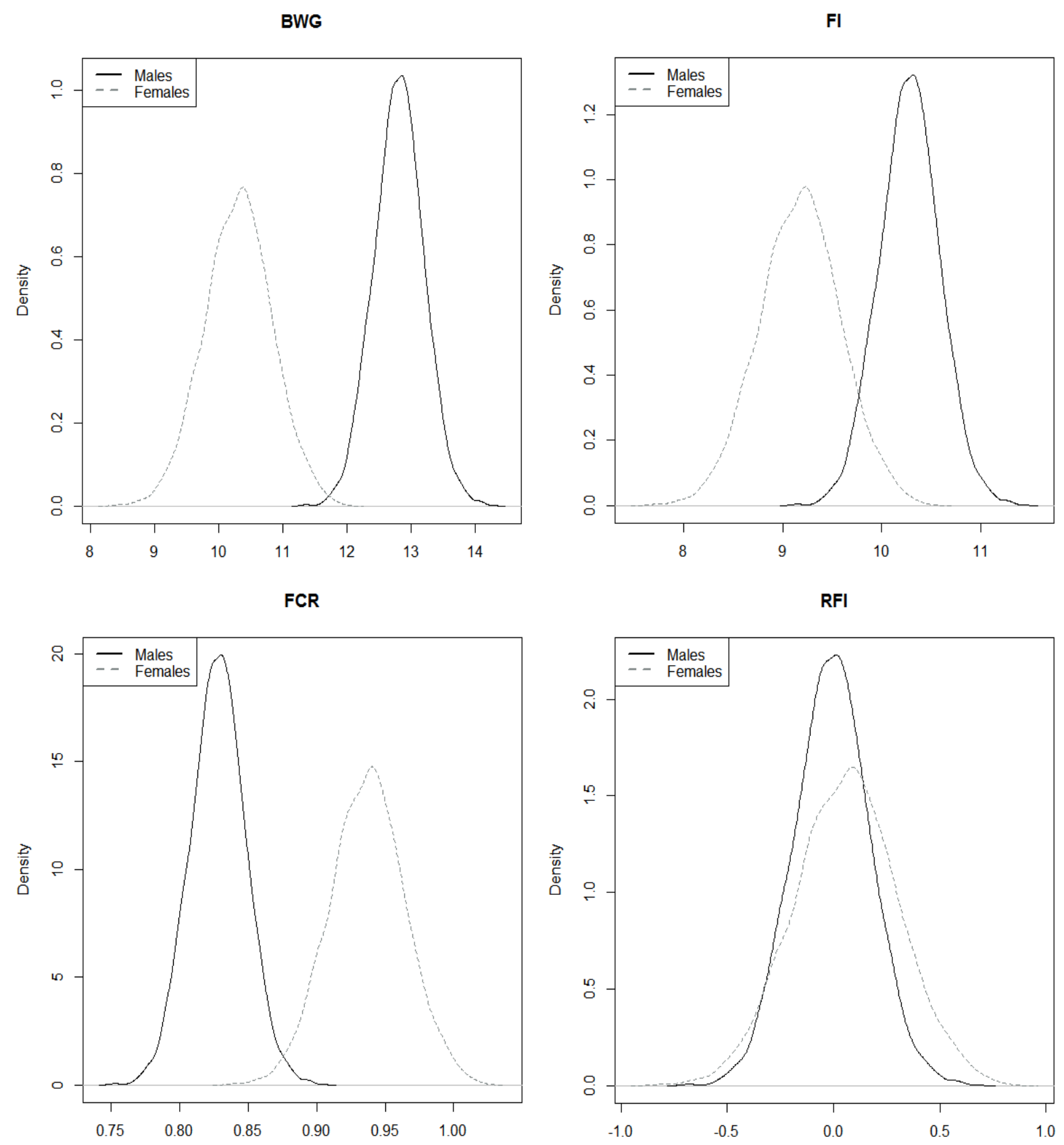
Figure 4

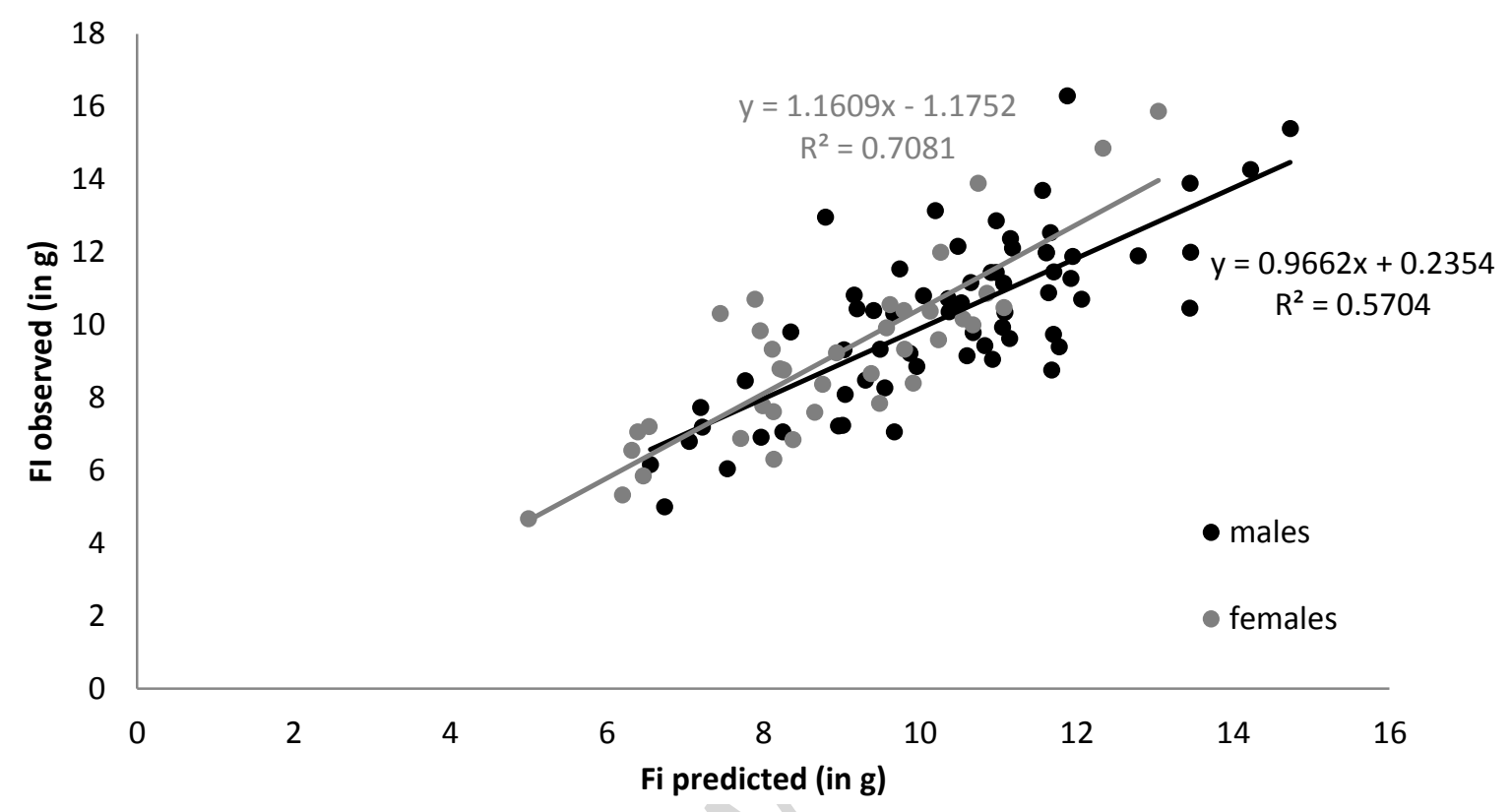




\begin{tabular}{cccccc}
\hline Meal & $\mathrm{N}$ & Mean & Min & Max & CV (\%) \\
\hline 1 & 107 & 0.53 & 0.08 & 0.90 & 33.60 \\
2 & 107 & 0.52 & 0.15 & 0.95 & 32.69 \\
3 & 107 & 0.45 & 0.05 & 0.98 & 40.28 \\
4 & 106 & 0.51 & 0.11 & 1.08 & 36.49 \\
5 & 106 & 0.49 & 0.07 & 1.01 & 34.78 \\
6 & 105 & 0.53 & 0.16 & 0.96 & 31.99 \\
7 & 105 & 0.47 & 0.03 & 1.03 & 39.36 \\
8 & 105 & 0.56 & 0.00 & 1.31 & 37.53 \\
9 & 105 & 0.41 & 0.00 & 0.93 & 49.85 \\
10 & 105 & 0.53 & 0.03 & 1.11 & 35.27 \\
11 & 105 & 0.47 & 0.00 & 1.29 & 42.18 \\
12 & 105 & 0.58 & 0.08 & 1.18 & 32.26 \\
13 & 105 & 0.52 & 0.03 & 1.05 & 36.19 \\
14 & 105 & 0.56 & 0.07 & 1.03 & 34.83 \\
15 & 105 & 0.52 & 0.10 & 1.06 & 35.11 \\
16 & 105 & 0.57 & 0.08 & 0.98 & 32.02 \\
17 & 105 & 0.54 & 0.08 & 1.01 & 30.04 \\
18 & 105 & 0.56 & 0.05 & 1.14 & 31.51 \\
19 & 104 & 0.56 & 0.11 & 1.16 & 31.97 \\
Overall & 104 & 0.52 & 0.00 & 1.31 & 36.25 \\
\hline
\end{tabular}

Table 1 - Summary statistics of individual feed intake (in g) at each measured meal. 


\begin{tabular}{lcccc}
\cline { 2 - 5 } & Male $(\mathrm{N}=65)$ & Female $(\mathrm{N}=37)$ & \multicolumn{2}{c}{$\begin{array}{c}\text { HPD } \\
\text { difference }\end{array}$} \\
\hline LOSS & $-0.07 \pm 0.03$ & $0.07 \pm 0.03$ & -0.26 & -0.003 \\
COMP & $16.40 \pm 0.46$ & $14.79 \pm 0.63$ & 0.06 & 3.21 \\
BWG & $12.81 \pm 0.39$ & $10.31 \pm 0.53$ & 1.17 & 3.84 \\
FI & $10.28 \pm 0.31$ & $9.17 \pm 0.41$ & 0.06 & 2.16 \\
FCR & $0.83 \pm 0.02$ & $0.94 \pm 0.03$ & -0.18 & -0.04 \\
RFI & $-0.007 \pm 0.18$ & $0.057 \pm 0.25$ & -0.69 & 0.56 \\
\hline
\end{tabular}

Table 2- Posterior least square means \pm posterior standard deviation and the HPD 95\% interval of difference between males and females for the measured performance traits. LOSS, the loss of body weight ( $\mathrm{g}$ ) during fasting period; COMP, the gain of body weight $(\mathrm{g})$ during compensatory growth; BWG, body weight gain (g); FI, feed intake total (g); FCR, feed conversion ration; and RFI, residual feed intake. 


\begin{tabular}{lccccc}
\hline Trait & $\mathrm{N}$ & $\begin{array}{r}\text { Mean } \pm \\
\text { StdDev }\end{array}$ & Min & Max & CV (\%) \\
\hline LOSS & 112 & $1.40 \pm 0.32$ & 0.34 & 1.09 & 22.6 \\
COMP & 107 & $15.9 \pm 3.87$ & 6.92 & 25.25 & 24.4 \\
BWG & 104 & $12.0 \pm 3.61$ & 3.32 & 20.78 & 30.2 \\
FI & 104 & $9.89 \pm 2.43$ & 4.68 & 16.30 & 24.6 \\
FCR & 104 & $0.86 \pm 0.20$ & 0.56 & 1.78 & 23.4 \\
RFI & 104 & $0.00 \pm 1.45$ & -2.99 & 4.41 & Ne \\
\hline
\end{tabular}

Table 3 - Summary statistics of variation of measured performance traits.

LOSS, the loss of body weight ( $\mathrm{g}$ ) during fasting period; COMP, the gain of body weight $(\mathrm{g})$ during compensatory growth; BWG, body weight gain (g); FI, feed intake total (g); FCR, feed conversion ration; and RFI, residual feed intake; Ne: non-estimable 


\begin{tabular}{lcccccc}
\hline Traits & COMP & BWG & FI & FCR & LogFCR & RFI \\
\hline LOSS & $\mathbf{0 . 3 5} \pm \mathbf{0 . 0 8}$ & $0.13 \pm 0.10$ & $\mathbf{0 . 2 4} \pm \mathbf{0 . 0 9}$ & $0.02 \pm 0.10$ & $0.06 \pm 0.10$ & $0.03 \pm 0.10$ \\
COMP & & $\mathbf{0 . 6 2} \pm \mathbf{0 . 0 6}$ & $\mathbf{0 . 6 6} \pm \mathbf{0 . 0 6}$ & $-0.11 \pm 0.10$ & $-0.12 \pm 0.10$ & $-0.01 \pm 0.10$ \\
BWG & & & $\mathbf{0 . 7 4} \pm \mathbf{0 . 0 5}$ & $\mathbf{- 0 . 6 2} \pm \mathbf{0 . 0 6}$ & $\mathbf{- 0 . 6 3} \pm \mathbf{0 . 0 6}$ & $-0.03 \pm 0.10$ \\
FI & & & & $-0.02 \pm 0.10$ & $0.00 \pm 0.10$ & $\mathbf{0 . 6 0} \pm \mathbf{0 . 0 6}$ \\
FCR & & & & & $\mathbf{0 . 9 9} \pm \mathbf{0 . 0 0}$ & $\mathbf{0 . 5 8} \pm \mathbf{0 . 0 6}$ \\
LogFCR & & & & & & $\mathbf{0 . 6 3} \pm \mathbf{0 . 0 6}$ \\
\hline
\end{tabular}

Table 4 - Posterior means of the correlations \pm posterior standard deviation between measured performance traits. The significant relationships are indicated in bold.

LOSS, the loss of body weight $(\mathrm{g})$ during fasting period; COMP, the gain of body weight $(\mathrm{g})$ during compensatory growth; BWG, body weight gain (g); FI, feed intake total (g); FCR, feed conversion ration; $\log \mathrm{FCR}, \log$ of feed conversion ration; and RFI, residual feed intake. 